\title{
Fatigue and microgap behaviour of a three-unit implant-fixed dental prosthesis combining conventional and dynamic abutments
}

José Rocha Ferreira, Nannan Song, Margarida Machado, Luís Machado, André Correia \& Ana Reis

\section{$\underline{\text { ABSTRACT }}$}

Study Design: This is an in vitro study composed by a fatigue test followed by an optical microscopy analysis.

Background: Dynamic abutments concept, recently introduced on screw-retained implant dental prosthesis, consists on the screw channel customization according to the individual needs of each rehabilitation. Geometry and tightening torque differences advise the assessment of their mechanical performance.

Objectives: Clarify whether the combination of dynamic and conventional abutments in a three-unit implant-fixed prosthesis, has detrimental effects either on the mechanical performance under cyclic loading or on the implant-abutment microgap dimensions.

Methods: The fatigue test was performed in agreement with the ISO standard 14801. Than on the samples that resisted 5 million cycles, the implant-abutment microgap was measured on dynamic and conventional abutments using optical microscopy. Two unloaded samples were used as control group. 
Results: The samples supported a load of 1050 N. The implant-abutment microgap measurement did not show statistically significant differences $(p=0,086)$ between loaded and unloaded groups, but the loaded conventional abutments showed a significant lower implant-abutment microgap $(p=0,05)$ than the loaded dynamic abutments.

Conclusions: The combination of conventional and dynamic abutments do not seem to produce a decrease in fatigue resistance to a level below the mastication forces or an increase in the joint dimensions.

204 words

KEYWORDS: dynamic abutments; Fatigue test; microgap

\section{MAIN TEXT}

\section{BACKGROUND}

Even if the long-term success of implant-supported fixed oral rehabilitations demands the prevention of any possible biological and mechanical complications ${ }^{(1)}$, the biomechanical behavior of dynamic abutments (DA) is scarcely reported in the literature $^{(2)}$. 
This concept consists of changing the screw channel from a position coincident with the implant major axis to an individual orientation (Fig.1). The DA allow a customized correction of the screw channel according to each prosthesis' needs, which indicates them for clinical situations where bone remodeling ${ }^{(3)}$ hinders a prosthetically driven implant placement ${ }^{(4,5)}$ or when there is a need to mend poor implant positioning. Thus, their use may prevent complex surgical interventions ${ }^{(6-11)}$ and represents an alternative to cemented prosthesis or angled abutments ${ }^{(12,13)}$.

There are two main differences from straight screw channel conventional abutments (CA): geometry (angulation of the screw channel and design of the screw (Figs. 1, 2, 3 and 4)) and tightening conditions (recommended $20 \mathrm{Ncm}$ ). Related to geometry and torque differences, there is the risk of screw loosening, which increases the microgap and micromovements ${ }^{(14)}$. Furthermore, combined with CA, a screw loosening could be clinically unnoticed, due to the presence of conventional screws, with a higher tightening torque $(35 \mathrm{Ncm})$. These effects require further attention to ensure safe long-term clinical applications. According to the authors' knowledge, there are no published studies accessing the biomechanical performance of DA in combination with CA.

Regardless of its variability ${ }^{(15-19)}$, several authors have reported similar values for the highest possible mastication force $\left(841 \mathrm{~N}^{(20,21)}\right.$ and $\left.847 \mathrm{~N}^{(22)}\right)$. The assessment of the maximum cyclic load that could be supported by an implant-supported dental 
fixed prosthesis combined with a CA and a DA, would clarify the mechanical safety of dynamic abutments. The fracture locations, when higher loads are used during the experiment, would reveal the weakest points on the implant-prosthesis assembly. Manzoor et al ${ }^{(23)}$, studying the likelihood of fracture location on the implant-abutment assembly components, found that when specimens with bone loss of $3 \mathrm{~mm}$ or more were tested, implant body fractures happened. In contrast, those with $1.5 \mathrm{~mm}$ of bone loss showed abutment and screw fractures.

The implant-abutment connection is colonized by bacteria ${ }^{(24)}$ and the bacterial contamination increases after cyclic loading as a result of a higher misfit ${ }^{(25,26)}$. This biofilm is dependent on the precision of fit between the components and the tightening torque used to connect them ${ }^{(14)}$. Nevertheless, Gehrke et al ${ }^{(27)}$ depicted a tendency to a decrease of the implant-abutment microgap (IAM) on loaded specimens. Scarano et al (28), after analyzing 170 retrieved implants, reported a mean microgap of $61.3 \mu \mathrm{m}$. In an in vitro study, Dias et al ${ }^{(29)}$, showed a mean IAM inferior to $3 \mu \mathrm{m}$. Considering that the microbial contamination affects the health of the biologic tissues around the osseointegrated implants ${ }^{(24)}$, the IAM analysis, after cyclic loading, might anticipate the biological behavior of DA.

Due to the differences with CA, in order to establish the safety of use of DA in combination with CA, the hypothesis under study was whether the inclusion of DA in a milled three-unit implant-fixed prosthesis would have detrimental effects either on the 
prosthesis mechanical performance under cyclic loading or on the IAM dimensions, resulting in an increased biofilm formation.

\section{MATERIALS AND METHODS}

The model tested on this experiment was a three-unit implant-supported fixed prosthesis composed of a DA, with the maximal angulation possible of the screw channel $\left(20^{\circ}\right)$, a pontic, and a CA with a vertical screw channel, obtained from milling technology. The prosthesis was screw retained on two Branemark external hexagon regular platform implants. The choice of this connection was influenced by the suggestion found in the bibliography ${ }^{(30,31)}$ correlating external connections with weaker biomechanical features. All the specimens tested were manufactured by the Avinent ${ }^{\circledR}$ Implant Company (Barcelona, Spain).

A fatigue test was performed, respecting the International Standard Organization (ISO) standard 14801. The fractures were analyzed to reveal patterns. To understand whether the cyclic loading had any effect on the microgap dimension, the samples that reached five million cycles were submitted to an optical microscope analysis to measure the IAM. As the control group, two non-loaded samples were also submitted to IAM measurement. The results were statistically analyzed with the Wilcoxon rank-sum test with the level of significance of $5 \%{ }^{(32,33)}$. For that propose the R Statistical Software ${ }^{(34)}$ was used (Free Software Foundation, Boston, USA). 


\subsection{Fatigue test}

To comply with ISO standard 14801, some tailor-made solutions were prepared ${ }^{(35)}$-to guarantee the correct implant positioning $\left(30^{\circ} \pm 1\right.$ with the load direction $)$ and the distance between the implant platform and the surface of the supporting epoxy resin (3 $\mathrm{mm}$ ). This resin constitutes the embedding substrate and should have a $3 \mathrm{GPa}$ Young's modulus. The load was applied to a semi-sphere modeled on the occlusal face of the pontic (Figs. 5, 6 and 7).

A total of thirteen samples were tested. To determine the maximum load that the assembly could resist, which corresponds to one cycle on the stress-number of cycles curve (S-N curve), three samples were submitted to a static load compressive test using a uniaxial universal Instron test machine (Norwood, MA, USA).

The remaining nine specimens were tested for progressively lower loads as depicted on table 1, using an MTS Test machine (Eden Prairie, MN, USA), resulting in the failure of the specimens 1 to 6 . When the applied load reached $1050 \mathrm{~N}$, the specimens remained intact after five million cycles (samples 8, 9 and 10). An intermediate load level (1275 N) was tried resulting in sample fracture (sample 7).

\subsection{Implant-abutment microgap (IAM) analysis}

The samples were divided into two groups (loaded - L and unloaded - UL), composed of two subgroups (conventional and dynamic). 
The $\mathrm{L}$ group consisted of the three specimens that resisted to compressive fatigue (samples 8, 9 and 10). These specimens, now designated as L-8, L-9, and L-10) were embedded in epoxy resin and vertically cut, parallel to the major axis of the implants to separate the CA from the DA. This process was performed by the use of the metallographic cutting machine Exotom 150 (Struers, Rotheram; UK), resulting in the loaded conventional subgroup $(n=3)$ and the loaded dynamic subgroup $(n=3)$. These six new specimens (3 loaded dynamic and 3 loaded conventional) were polished to reach the center of the implant-abutment complex by the use of the semi-automatic metallographic polisher Pedemax-2 (Struers, Rotheram; UK) (fig.8).

The same procedure was performed to prepare two UL assemblies, the control group (UL-A, UL-B), resulting in the unloaded conventional subgroup $(n=2)$ and the unloaded dynamic subgroup ( $\mathrm{n}=3)$.

The specimens were analyzed with an optical emission microscope (PMG3 Olympus, Tokyo, Japan) with 1,000x magnification. Measurements were performed by using the digital system Olympus DP-soft and photos were taken with the digital photographic machine Olympus DP-12. Each IAM was visualized in six microscopic fields and at least four measurements were carried out for each.

In this experiment, since small sized groups or subgroups were under study, it was not possible to ascertain the normality assumption. In these cases, a nonparametric test is the recommended approach. Due to this fact, to access the statistical significance 
of the obtained measurements, the Wilcoxon rank-sum test was used. This is a very robust test only requiring the continuous or at least ordinal data and the independence of both groups.

\section{RESULTS}

\subsection{Fatigue test}

Regarding the static load compressive test $(n=3)$, a maximum force of $3005 \mathrm{~N}$ was reported until failure.

The progressive reduction of the applied load to $2400 \mathrm{~N}, 1950 \mathrm{~N}$ and $1500 \mathrm{~N}$, under fatigue tests, resulted in specimens' failure (samples 1, 2, 3, 4, 5, and 6). When the applied load was equal to $1050 \mathrm{~N}$, the three specimens tested (samples 8,9 and 10) remained intact after five million cycles. An intermediate load level $(1275 \mathrm{~N})$ was tried resulting in sample fracture (sample 7).

These results demonstrate that the specimens could support a load in the interval between $1050 \mathrm{~N}$ and $1275 \mathrm{~N}$ along 5 million cycles (Table1 and Fig 9).

It is important to mention that all fractures were reported on the implants, at the supporting epoxy resin level (Fig 10), excepting one situation where the fracture occurred on the screw. 


\subsection{Implant-abutment microgap analysis}

The IAM was measured with a magnification of 1,000x. By analyzing the measurements, it was possible to observe a small microgap value for all the specimens. Regarding the control group, the highest values were found on the same sample (UL-B), either on the conventional subgroup $(12.8 \mu \mathrm{m})$ or on the dynamic subgroup $(7.10 \mu \mathrm{m})$. Considering the L group, the highest measurement $(3.81 \mu \mathrm{m})$ was found on the L-9 sample from dynamic subgroup. The loaded conventional subgroup showed more minor microgaps than loaded dynamic subgroup (Table 2, Figs. 11 and 12).

The conventional specimens UL-A, L-9, and L-10, showed such a small IAM for some microscopic fields that it was impossible to quantify with optical microscopy (Fig. 13). The value zero was considered for the measurement on those points and that effect is reflected in the final value.

The non-parametric Wilcoxon rank-sum test was chosen to compare the central tendency between the studied populations. Regarding the L group, the null hypothesis under study considered that there was no difference between the medians of the two subgroups (conventional and dynamic). As can be seen on the boxplot (fig. 14), the median for the conventional loaded subgroup $(0.65 \mu \mathrm{m})$ is clearly different from the median of the dynamic loaded subgroup $(2.92 \mu \mathrm{m})$. Results from a one tailored analysis of the Wilcoxon rank-sum test allowed the conclusion that the IAM, on the 
conventional loaded subgroup, was lower than on the dynamic loaded subgroup (exact $p$-value $=0.05)$, rejecting therefore the null hypothesis.

Comparing the central tendencies of the loaded and unloaded group (fig. 15), with recourse to the same statistical test, the null hypothesis established that there were no differences between the two groups. Although the median of the loaded group (2.6 $\mu \mathrm{m})$ was lower than the median of the unloaded group $(5.21 \mu \mathrm{m})$, the comparison between both groups (one tailored analysis) did not allow the rejection of the null hypothesis for a confidence level of $5 \%$ (exact $p$-value $=0.086$ ).

\section{DISCUSSION}

\subsection{Fatigue test}

The results of this study point to a value between $1050 \mathrm{~N}$ and $1275 \mathrm{~N}$, where it is expected that the tested specimens would have an increased life span. As these forces were applied with a $30^{\circ}$ slope, they have a vertical component between $909 \mathrm{~N}$ and 1104 $\mathrm{N}$, and a horizontal component between $525 \mathrm{~N}$ and $637 \mathrm{~N}$.

These results indicate that the inclusion of DA does not affect the mechanical performance of the prosthesis under cyclic loads. The prosthesis fracture may occur for a vertical load of $909 \mathrm{~N}$, value above the $841 \mathrm{~N}$ and $847 \mathrm{~N}$ described by Baca et al, Lindquist et al and Waltimo et al for the maximum vertical occlusion force ${ }^{(20-22)}$. 
As no study published on this issue came to the authors' knowledge, and due to the enormous variety of methodologies described for fatigue tests, the choice of ISO standard14801 is related to the fact that it establishes a methodology that can be replicated by different future studies on the same subject, allowing a valid comparison between possible different results.

All but one of the fractures were found on the implants at embedding level. These results are aligned with Manzoor et al ${ }^{(23)}$ once the $3 \mathrm{~mm}$ distance between the implant platform and the substrate corresponds clinically, to the biological width organization, resulting in a distant marginal bone level. Thus, the choice of the implantabutment connection, as a critical factor to preserve the bone level, could be of more critical importance than the use of DA. Furthermore, the ISO standard should consider different clinical scenarios with implant-abutment connections related with bone loss inferior to $3 \mathrm{~mm}$.

\subsection{Implant-abutment microgap analysis}

The comparison between the loaded and unloaded groups did not allow for the rejection of the null hypothesis, meaning that the found differences were not statistically significant. Nevertheless, the results seem to depict a tendency to a decrease of the IAM on the loaded specimens, what suggest that the inclusion of DA does not have a negative effect. This is an important finding once a detrimental effect of the inclusion of 
DA would be an increase on the IAM, exactly the opposite of what the results suggest. Similar results have already been reported in bibliography. Contrarily to the studies of Nascimento et al ${ }^{(25)}$ and Hoyer et al ${ }^{(26)}$, that reported a joint opening after loading, Gehrke et al ${ }^{(27)}$, studying four implant-abutment samples with internal connections, found a significant lower microgap after cyclic loading. It is worth mentioning, however, that one possible reason for the present study not being able to obtain a statistically significant difference between the two groups, could be explained by the reduced number of samples in each group. This possibility is sustained on the fact that the p-value $(0.086)$ is approaching 0.05 , value with which the difference would be considered statistically significant.

Comparing dynamic and conventional abutments after loading, a statistically significant lower IAM could be found on the CA, which allowed for the rejection of the null hypothesis. Nevertheless, confronted with previous publications, the present study shows lower values than those reported on clinical studies. Scarano et al ${ }^{(28)}$, measuring the microgap on 272 retrieved implants, found an IAM mean of $61.3 \mu \mathrm{m}$ on 170 screwretained prosthesis and an IAM mean of $40.4 \mu \mathrm{m}$ on 102 cement-retained prosthesis. Compared with in vitro studies, this experiment obtained similar results. Dias et al ${ }^{(29)}$, comparing the IAM on external hexagon implants from five different companies, concluded that it was lower than $3 \mu \mathrm{m}$ for all specimens. 
It is also worth mentioning that the referred studies have not elucidated whether casting or milling technologies were used to obtain the samples. This information is considered of paramount importance once the scientific evidence indicates a better fit of milled structures ${ }^{(36-39)}$.

These results can also be discussed, taking into consideration the differences between experimental and clinical conditions. Clinically, the plaster models preparation requires the use of materials with dimensional variations within the curing process. Overcoming these issues, the tested specimens were obtained by a milling process directly from computer assisted design. The implants and screws were provided by the same company. As a result, the adaptation between the components of each specimen showed an excellent passive fit that is difficult to recreate under clinical conditions, what constitutes a limitation for the clinical extrapolation of the results obtained on the present experiment. For this reason, the conduction of prospective clinical trials, which could be compared with the present study, would be an important future research.

\section{CONCLUSIONS}

The experimental tests performed did not show that the inclusion of DA in a milled framework would have a negative impact either on its mechanical performance under cyclic loading or on the IAM dimensions. The fatigue test results indicate that the samples would resist to a load correspondent to the maximum biting force value found 
in the bibliography and the IAM measurements showed that the cyclic load did not contribute to open the joint.

Within the limitations of this study, the geometrical differences and the lower tightening torque do not seem to have any detrimental influence on the analyzed parameters, when a DA is used in combination with a CA, suggesting its safety of use.

However, more in vitro studies and clinical trials are needed to confirm this conclusion.

Word count: 2599 words

\section{ACKNOWLEDGMENTS}

The authors gratefully acknowledge the Avinent ${ }^{\circledR}$ Implant Company for their collaboration in providing the specimens tested.

The authors also acknowledge the INEGI for the preparation of the necessary tailor-made solutions to respect the ISO standard 14801.

The study was supported in part by SciTech - Science and Technology for Competitive and Sustainable Industries, and the R\&D project was cofinanced by the North Portugal Regional Operational Program ("NORTE2020") and the European Regional Development Fund (FEDER). 
The authors declare no conflicts of interest.

\section{REFERENCES}

1. Cibirka RM, Nelson SK, Lang BR, et al. Examination of the implant-abutment interface after fatigue testing. J Prosthet Dent. 2001; 85:268-75.

2. Berroeta E, Zabalegui I, Donovan T, et al. Dynamic abutment: a method of redirecting screw access for implant-supported restorations: technical details and a clinical report. J Prosthet Dent. 2015; 113(6): 516-519.

3. Lekholm U, Zarb G. Patient selection and preparation. In: Branemark P-I, Zarb G, Albrektsson T, editors. Tissue-integrated Prostheses Osseointegration in Clinical Dentistry: Quintessence; 1985. p. 199-209.

4. Spinelli D, Ottria L, De Vico G, et al. Full rehabilitation with nobel clinician ${ }^{\circledR}$ and procera implant bridge ${ }^{\circledR}$ : case report. Oral Implantol. 2013; 2:25-36.

5. Rosenfeld A, Mandelaris G, Tardieu P. prosthetically directed implant placement using computer software to ensure precise placement and predictable prosthetic outcomes. Part 2: rapid-prototype medical modelling and stereolithographic drilling guides requiring bone exposure. Int J Periodontics Restorative Dent. 2006; 26:34753.

6. Urban I, Jovanovic S, Lozada J. Vertical ridge augmentation using guided bone regeneration (gbr) in three clinical scenarios prior to implant placement: a 
retrospective study of 35 patients 12 to 72 months after loading. Int J Oral Maxillofac Implants. 2009; 24:502-10.

7. Urban I, Nagursky H, Lozada J. Horizontal ridge augmentation with a resorbable membrane and particulated autogenous bone with or without anorganic bovine bone-derived mineral: A prospective case series in 22 patients. Int J Oral Maxillofac Implants. 2011; 26:404-14.

8. Urban I, Lozada JL, Jovanovic SA, et al. Vertical ridge augmentation with titanium-reinforced, dense-ptfe membranes and a combination of particulated autogenous bone and anorganic bovine bone-derived mineral: a prospective case series in 19 patients. Intl J Oral Maxillofac implants. 2013; 29:185-93.

9. Esposito M, Grusovin MG, Felice P, et al. The efficacy of horizontal and vertical bone augmentation procedures for dental implants-a cochrane systematic review. Eur J Oral Implantol. 2009; 2:167-84.

10. Tonetti MS, Hämmerle CHF, on behalf of the European workshop on periodontology group C. Advances in bone augmentation to enable dental implant placement: consensus report of the sixth European workshop on periodontology. J Clin Periodontol 2008; 35:168-72.

11. Chiapasco M, Casentini $\mathrm{P}$, Zaniboni $\mathrm{M}$. Bone augmentation procedures in implant dentistry. Int J Oral Maxillofac Implants. 2009; 24:237-259. 
12. Sailer I, Mühlemann S, Zwahlen M, et al. cemented and screw-retained implant reconstructions: a systematic review of the survival and complication rates. Clin Oral Implants Res. 2012; 23:163-201.

13. Gotfredsen K, Wiskott A, Working G. Consensus report - reconstructions on implants. The third EAO consensus conference 2012. Clin Oral Implants Res. $2012 ; 23: 238-41$.

14. Steinebrunner L, Wolfart S, Bössmann K, et al. In vitro evaluation of bacterial leakage along the implant-abutment interface of different implant systems. Int J Oral Maxillofac Implants. 2005; 20:875-81.

15. Motegi E, Nomura M, Tachiki C, et al. Occlusal force in people in their sixties attending college for elderly. Bull Tokyo Dent Coll. 2009; 50:135-40.

16. Helkimo E, Carlsson GE, Helkimo M. Bite force and state of dentition. Acta Odontol Scand. 1977; 35:297-303.

17. Ikebe K, Nokubi T, Morii K, et al. Association of bite force with ageing and occlusal support in older adults. J Dent. 2005; 33:131-7.

18. Sathyanarayana HP, Premkumar S, Manjula W. Assessment of maximum voluntary bite force in adults with normal occlusion and different types of malocclusions. J Contemp Dent Pract 2012; 13:534-8. 
19. Johnsen SE, Svensson KG, Trulsson M. Forces applied by anterior and posterior teeth and roles of periodontal afferents during hold-and-split tasks in human subjects. Exp Brain Res. 2007; 178:126-34.

20. Baca E, Yengin E, Gökçen-Röhlig B, et al. In vivo evaluation of occlusal contact area and maximum bite force in patients with various types of implant-supported prostheses. Acta Odontol Scand. 2013; 7:1181-7.

21. Lindquist LW, Carlsson GE. Long-term effects on chewing with mandibular fixed prostheses on osseointegrated implants. Acta Odontol Scand. 1985; 43:39-45.

22. Waltimo A, Könönen M. Maximal bite force and its association with signs and symptoms of craniomandibular disorders in young finish non-patients. Acta Odontol Scand. 1995; 53:254-8.

23. Manzoor B, Suleiman M, Palmer RM. The effects of simulated bone loss on the implant-abutment assembly and likelihood of fracture: an in vitro study. Int J Oral Maxillofac Implants. 2013; 28(3):729-38.

24. Piattelli A, Scarano A, Paolantonio M, et al. Fluids and microbial penetration in the internal part of cement-retained versus screw-retained implant-abutment connections. J Periodontol. 2001; 72:1146-50.

25. Nascimento C, Miani P, Vinícius $\mathrm{P}$, et al. leakage of saliva through the implantabutment interface: in vitro evaluation of three different implant connections under unloaded and loaded conditions. Int J Oral Maxillofac Implants. 2012; 27:551-60. 
26. Hoyer S, Stanford C, Buranadham S, et al. dynamic fatigue properties of the dental implant-abutment interface: joint opening in wide-diameter versus standarddiameter hex-type implants. J Prosthet Dent. 2001; 85:599-607.

27. Gehrke S, Pereira A. Changes in the abutment-implant interface in morse taper implant connections after mechanical cycling: a pilot study. Int J Oral Maxillofac Implants. 2014; 29:791-7.

28. Scarano A, Assenza B, Piattelli M, et al. A 16-year study of the microgap between 272 human titanium implants and their abutments. J Oral Implantol. 2005; 31:26975.

29. Dias E, Bisognin E, Harari N, et al. evaluation of implant-abutment microgap and bacterial leakage in five external-hex implant systems: an in vitro study. Int J Oral Maxillofac Implants. 2012; 27:346-51.

30. Yamanishia Y, Yamaguchia S, Imazatoa S, et al. influences of implant neck design and implant-abutment joint type on peri-implant bone stress and abutment micromovement: three-dimensional finite element analysis. Dent Mater. 2012; 28:1126-33.

31. Feitosa P, de Lima A, Silva-Concílio L, et al. stability of external and internal implant connections after a fatigue test. Eur J Dent. 2013; 7:267-71.

32. Wilcoxon F. Individual comparisons by ranking methods. Biometrics Bulletin. $1945 ; 1: 80-3$. 
33. Mann HB, Whitney DR. On a test of whether one of two random variables is stochastically larger than the other. Annals of Mathematical Statistics. 1947; 18:5060.

34. The R project for statistical computing [internet]. Vienna: GNU project. Available from: https://www.r-project.org

35. The international organization for standardization (ISO). Dentistry. Fatigue test for endosseous dental implants. Geneva: ISO; 2007. Standard nr 14801-2007(E).

36. Ortorp A, Jemt T, Bäck T, et al. comparisons of precision of fit between cast and cnc-milled titanium implant frameworks for the edentulous mandible. Int $\mathrm{J}$ Prosthodont 2003; 16:194-200.

37. Sierraalta M, Vivas J, Razzoog M, et al. Precision of fit of titanium and cast implant frameworks using a new matching formula. Int J Dent. 2012; 2012:9.

38. Karl M, Holst S. strain developments of screw-retained implant-supported fixed restorations: procera implant bridge versus conventionally cast restorations. Int J Prosthodont. 2012; 25:166-9.

39. Almasri R, Drago C, Siegel S, et al. Volumetric misfit in CAD/CAM and cast implant frameworks: a university laboratory study. J Prosthond. 2011; 20:267-74. 
Table 1 -Fatigue test results

With a maximum load of $1050 \mathrm{~N}$, three specimens completed the 5 million cycles without fracture.

\begin{tabular}{|c|c|c|c|}
\hline Specimen & Level $(\%)^{* 1}$ & Load $(\mathrm{N})^{*_{2}}$ & $\begin{array}{c}\text { Results (number of } \\
{\text { cycles })^{* 3}}^{*}\end{array}$ \\
\hline 1 & 80 & 2400 & 480 \\
\hline 2 & 80 & 2400 & 699 \\
\hline 3 & 65 & 1950 & 4,887 \\
\hline 4 & 65 & 1950 & 156,547 \\
\hline 5 & 50 & 1500 & 10,176 \\
\hline 6 & 50 & 1500 & $3,424,208$ \\
\hline 7 & 42.5 & 1275 & $5,000,000$ \\
\hline 8 & 35 & 1050 & $5,000,000$ \\
\hline 9 & 35 & 1050 & $5,000,000$ \\
\hline 10 & & 1050 & \\
\hline
\end{tabular}

${ }^{* 1}$ - The second column represents the relation between the applied load and the static load compressive test result. 
*2 - The third column represents the maximum load applied in each cycle.

*3 - The last column represents the number of cycles before the interruption of the test.

Table 2 - IAM analysis

\begin{tabular}{|c|c|c|c|c|c|}
\hline \multirow{2}{*}{} & \multicolumn{2}{|c|}{ Unloaded } & \multicolumn{3}{c|}{ Loaded } \\
\cline { 2 - 6 } & UL-A & UL-B & L-8 & L-9 & L-10 \\
\hline Conventional abutments & $0.9 \mu \mathrm{m}$ & $12.8 \mu \mathrm{m}$ & $2.44 \mu \mathrm{m}$ & $0.5 \mu \mathrm{m}$ & $0.65 \mu \mathrm{m}$ \\
\hline Dynamic abutments & $3.32 \mu \mathrm{m}$ & $7.10 \mu \mathrm{m}$ & $2.76 \mu \mathrm{m}$ & $3.81 \mu \mathrm{m}$ & $2.92 \mu \mathrm{m}$ \\
\hline
\end{tabular}


Figure 1

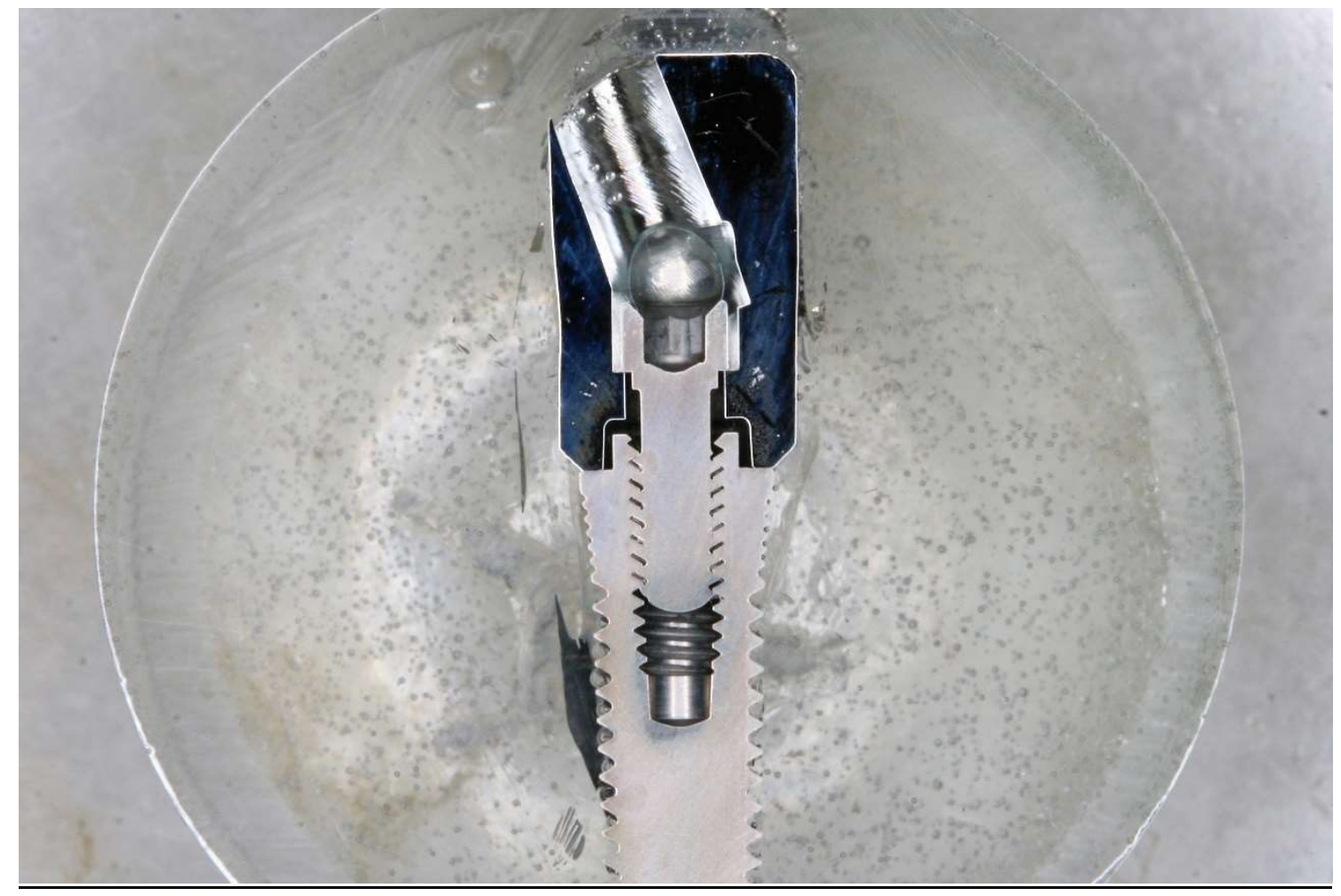


Figure 2

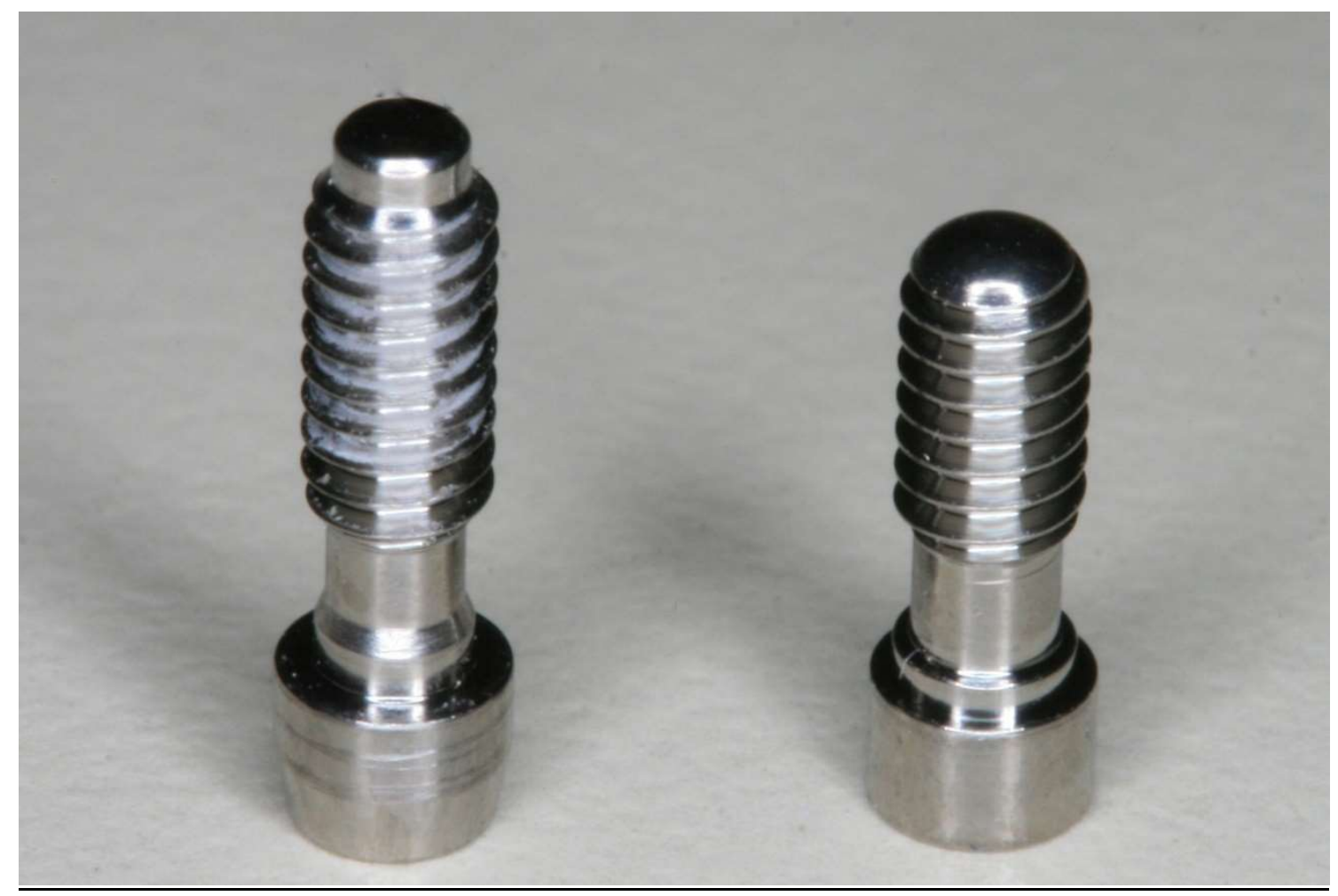


Figure 3

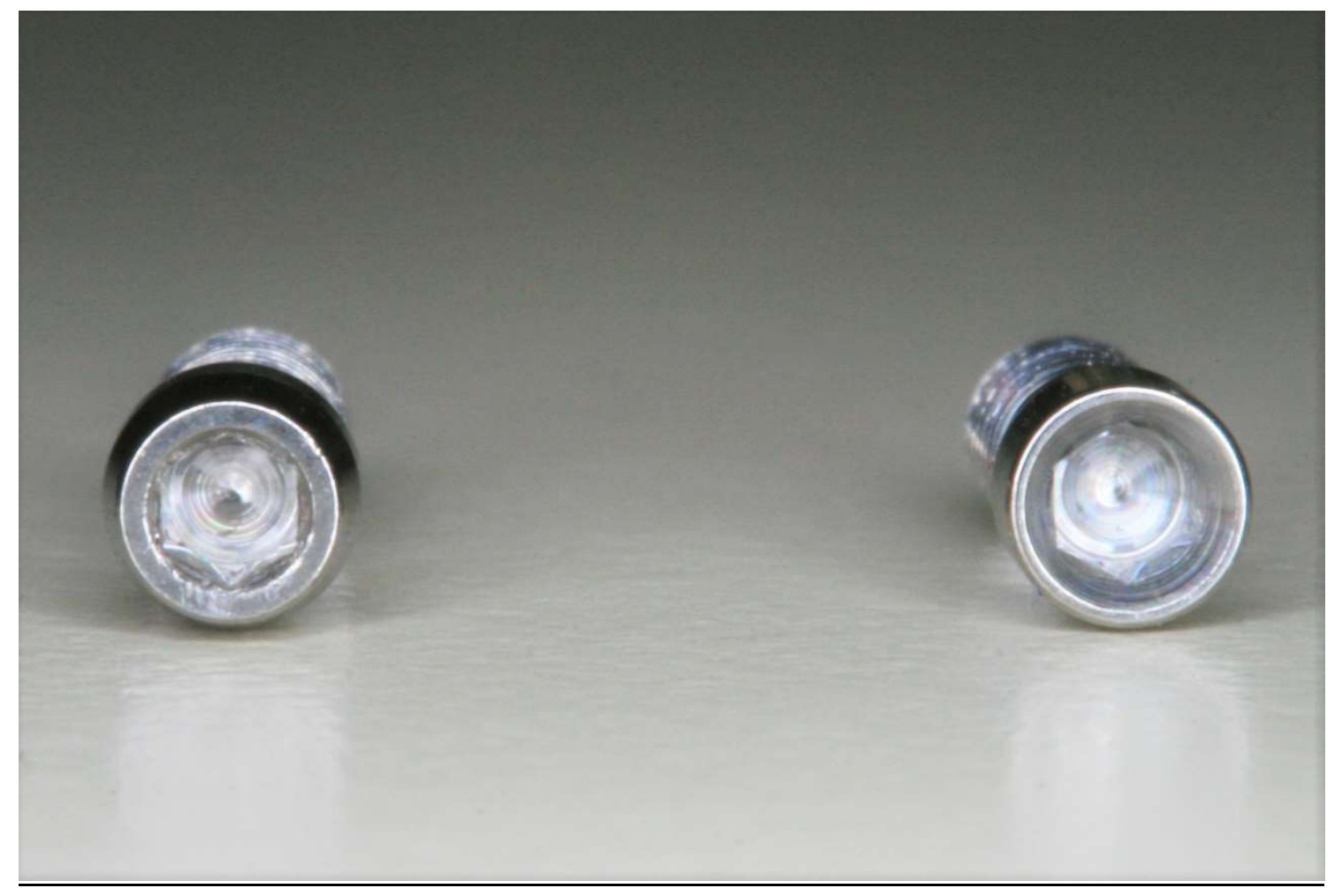


Figure 4 


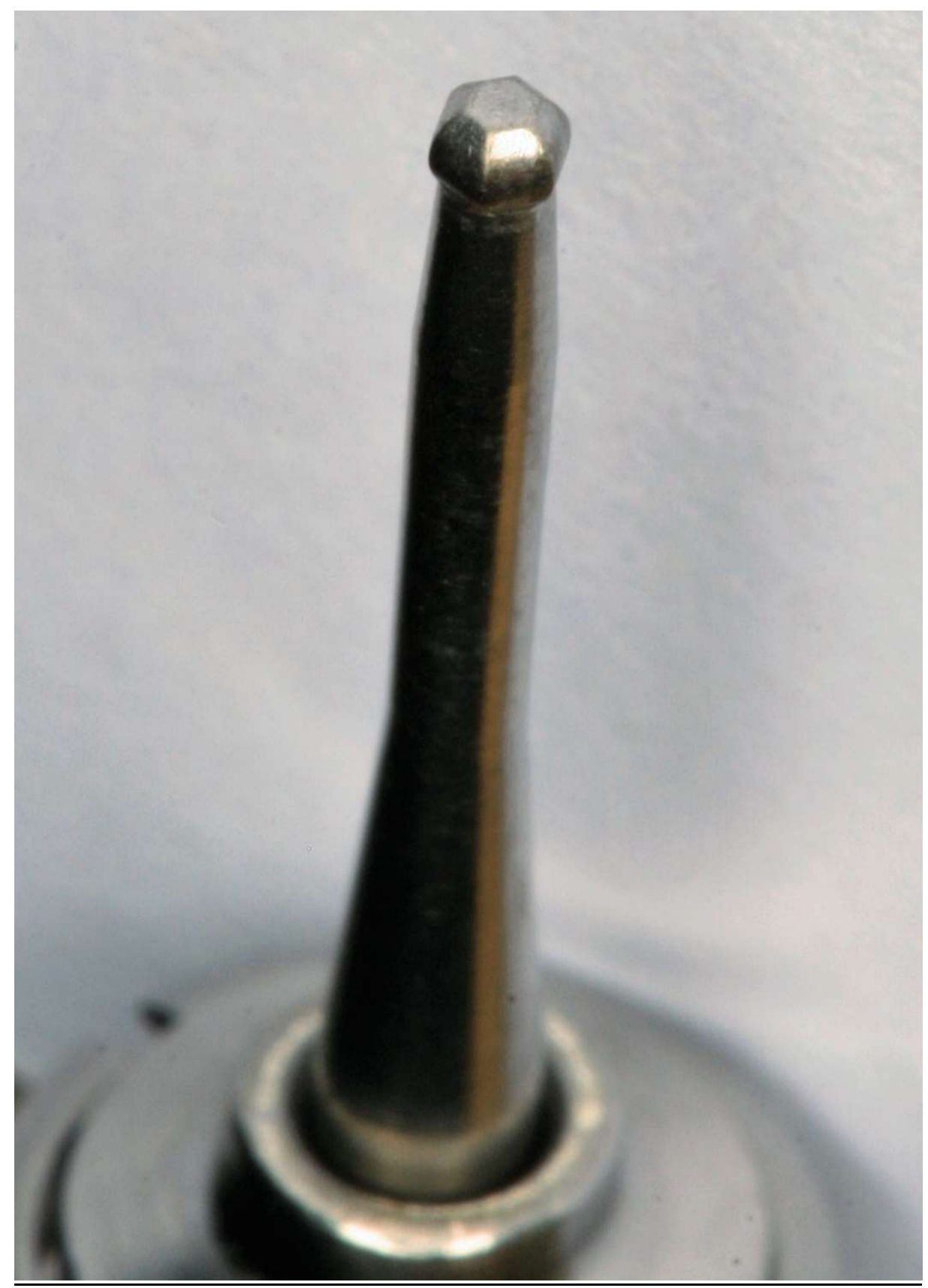


Figure 5

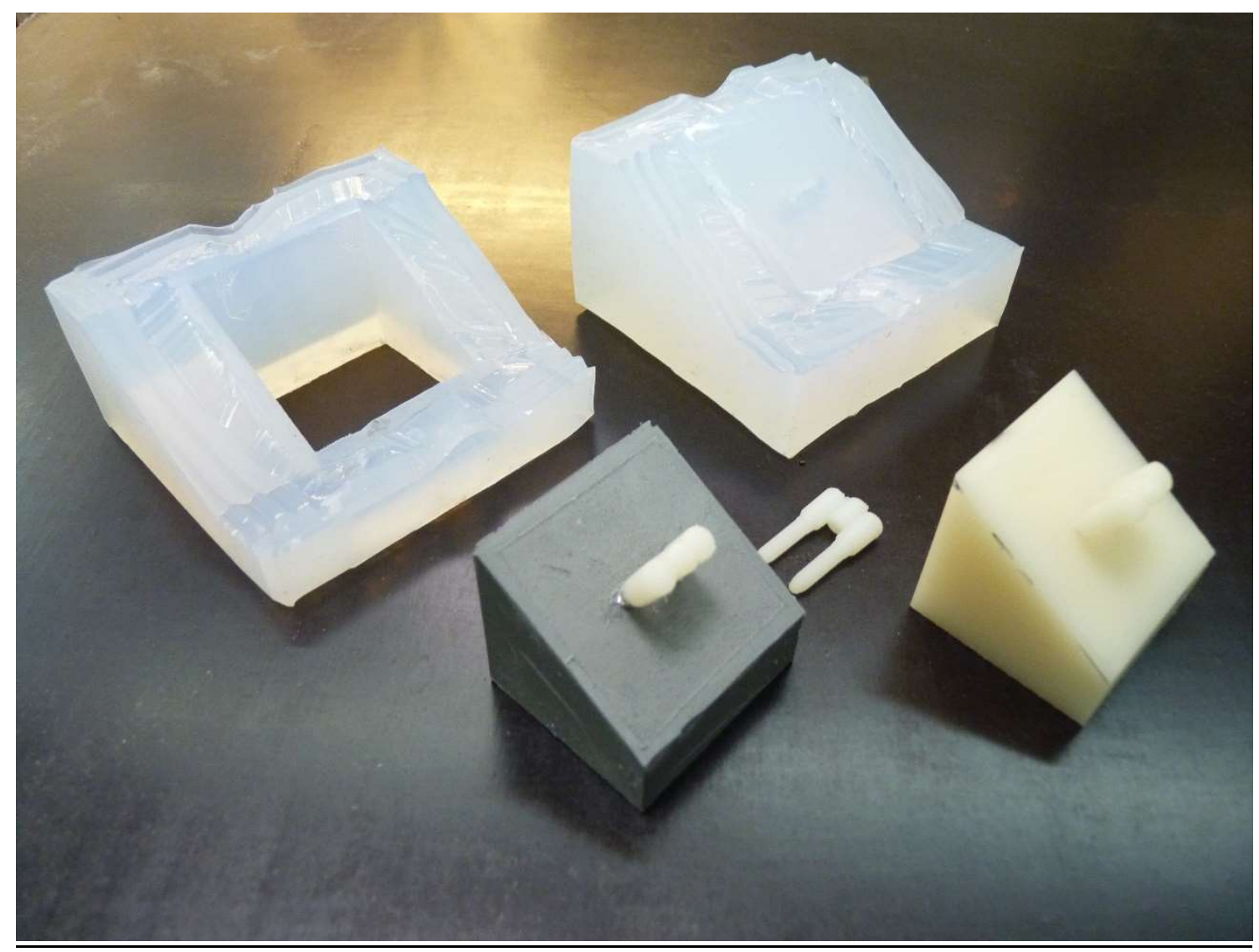


Figure 6

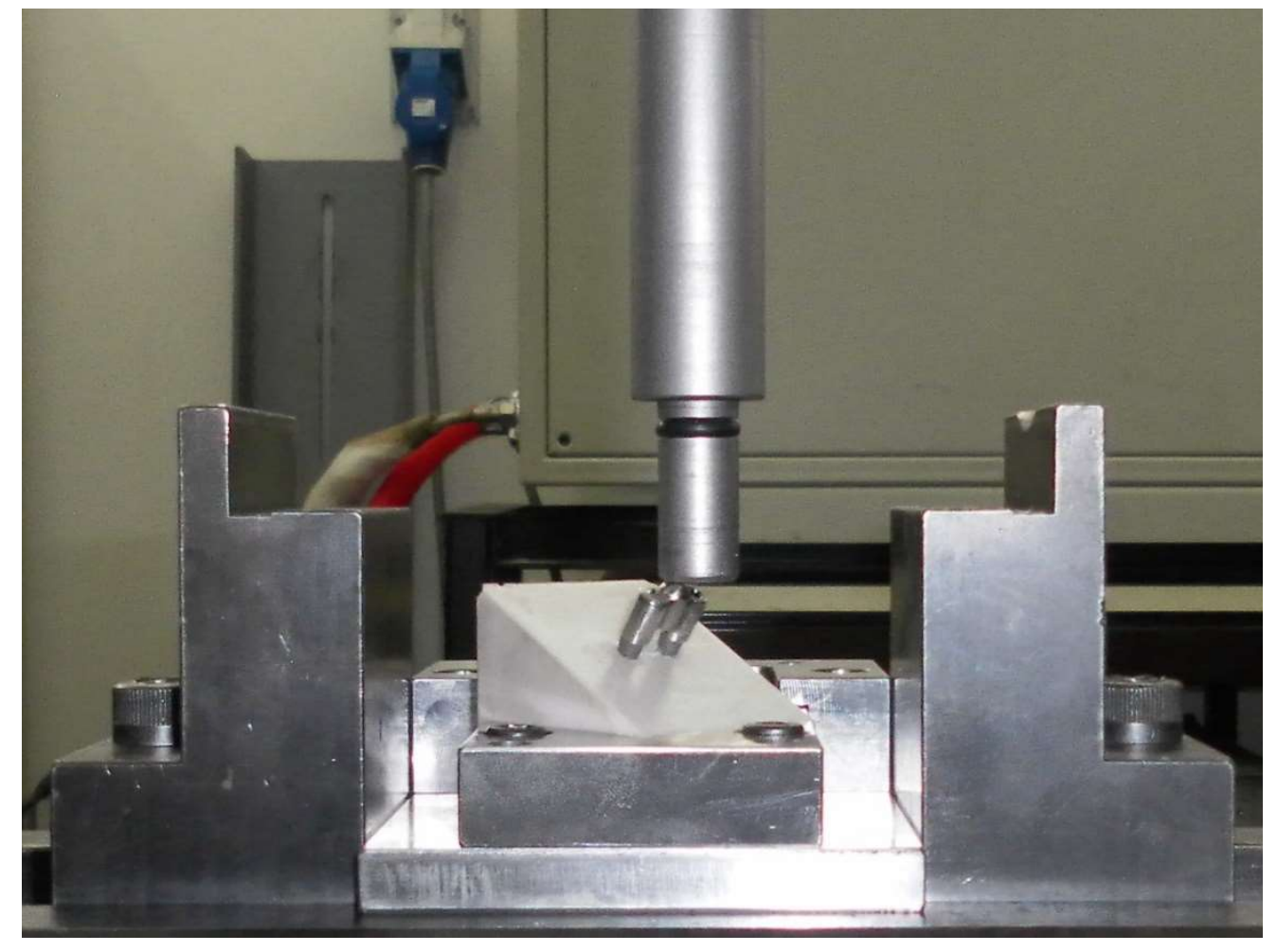


Figure 7

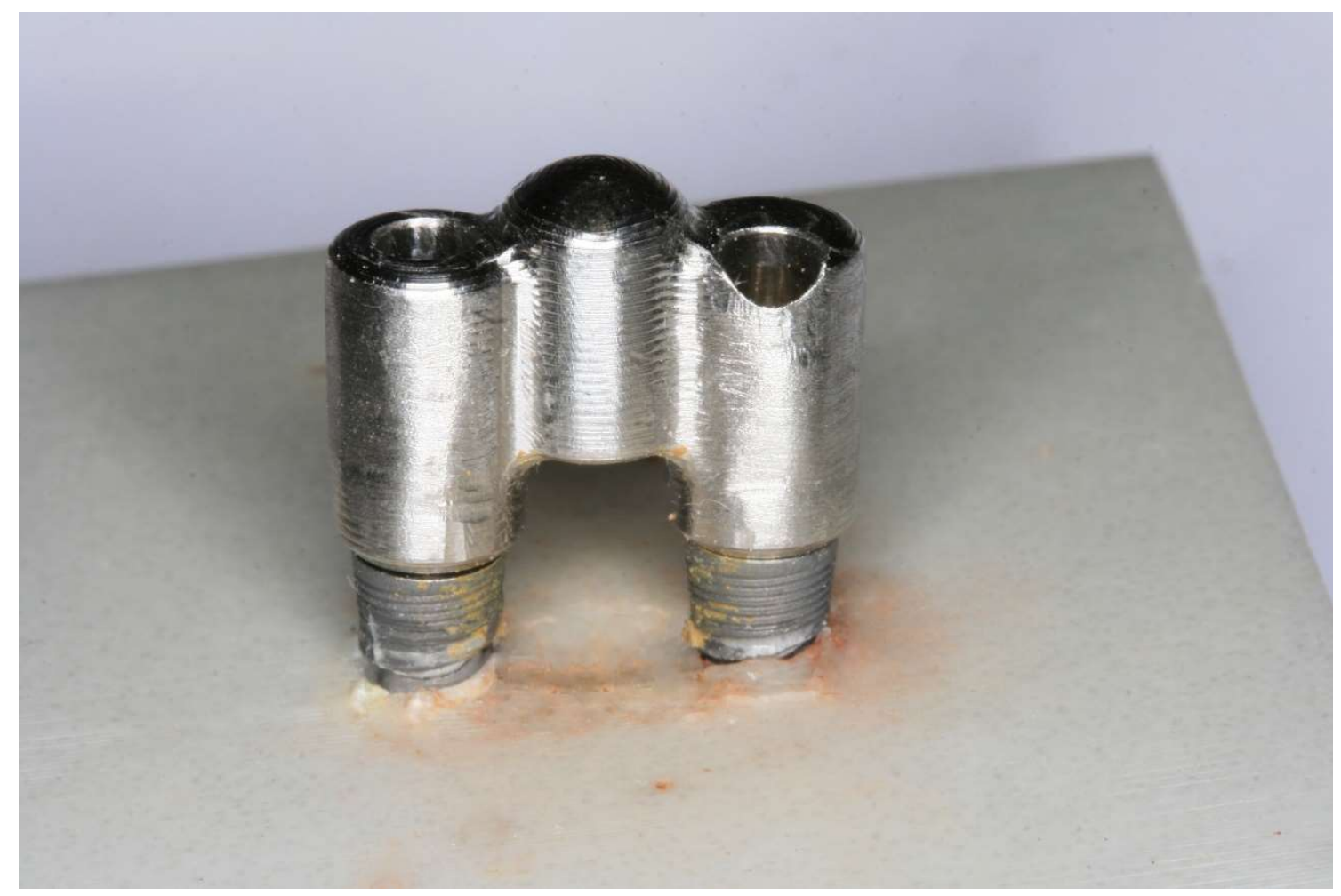

Figure 8 


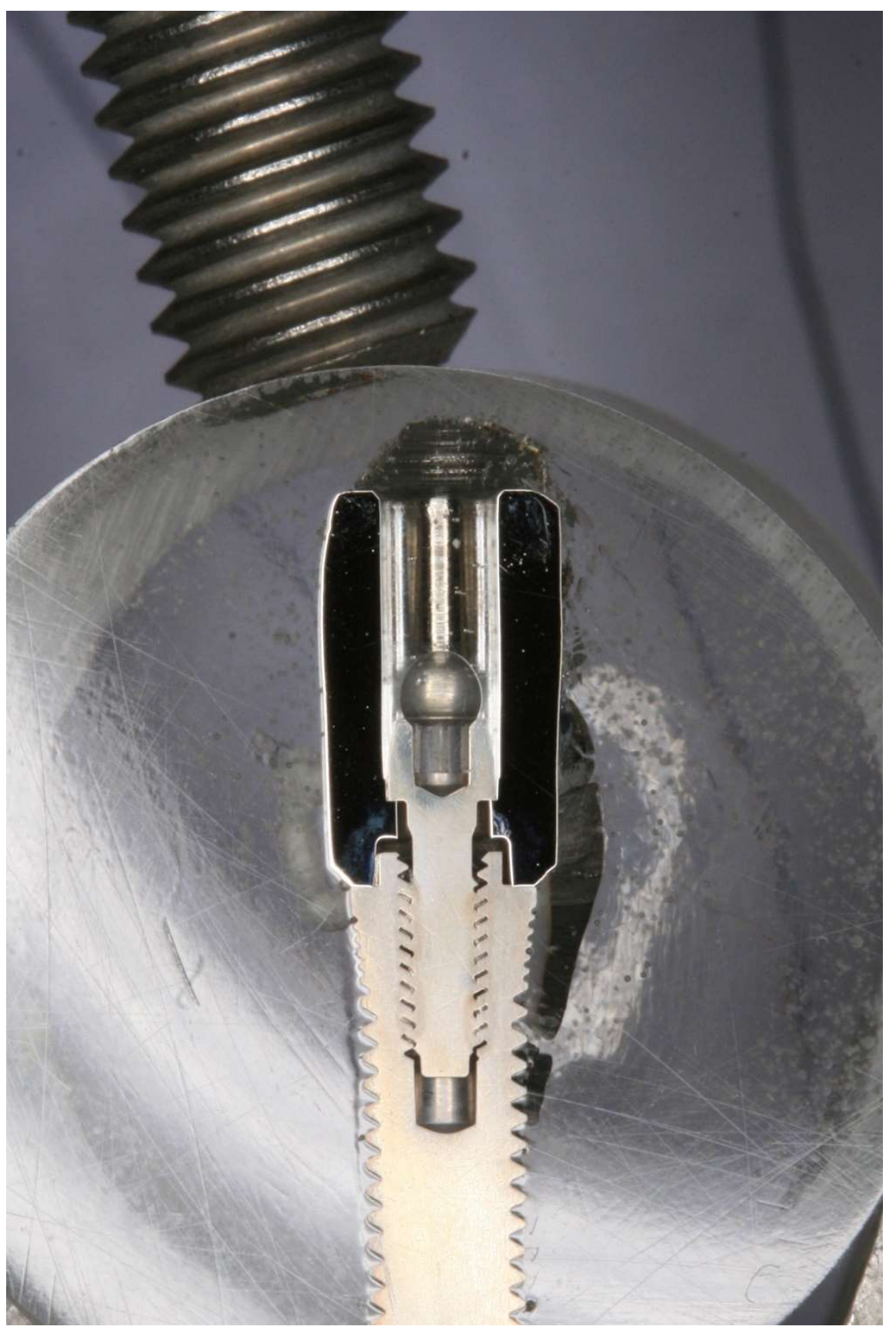


Figure 9

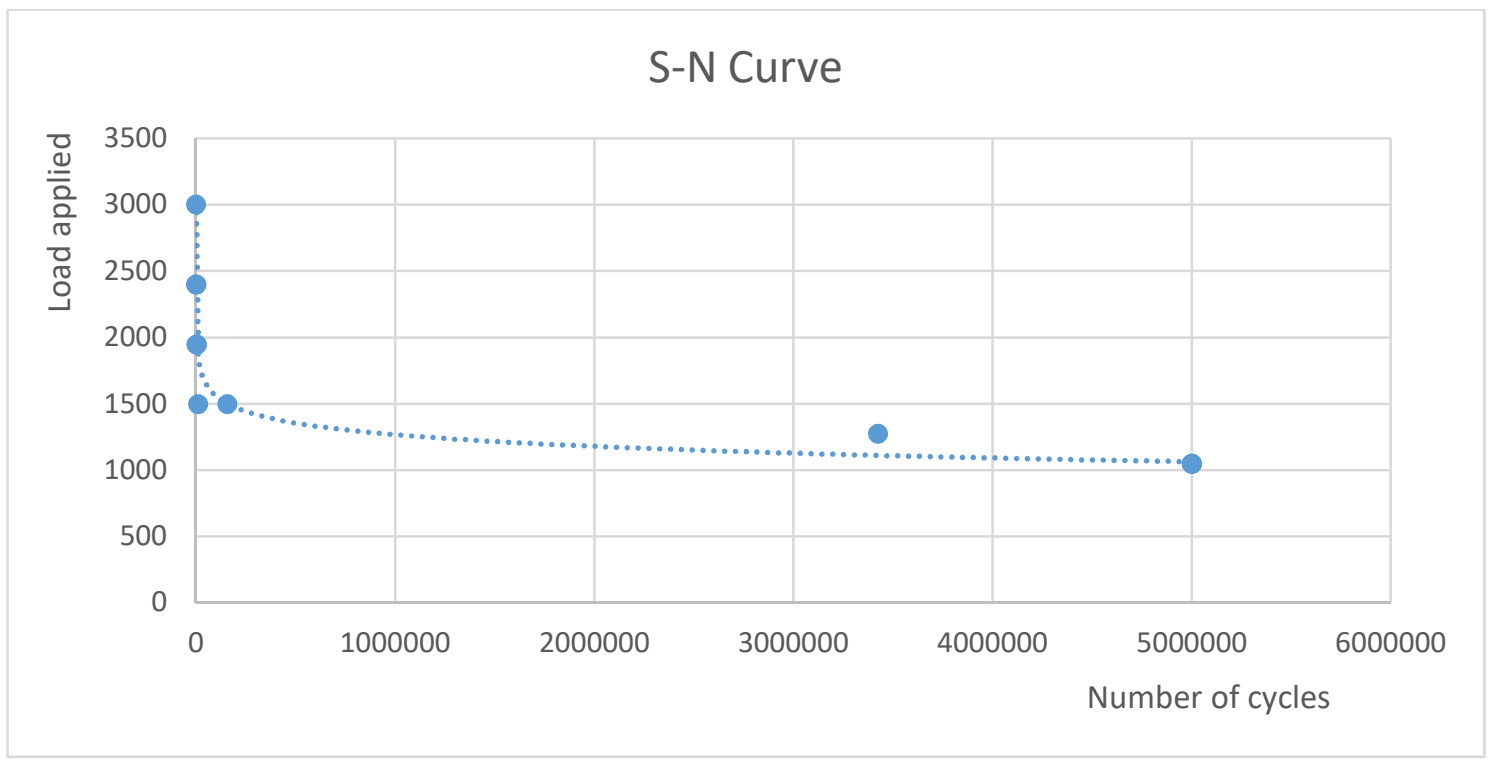


Figure 10

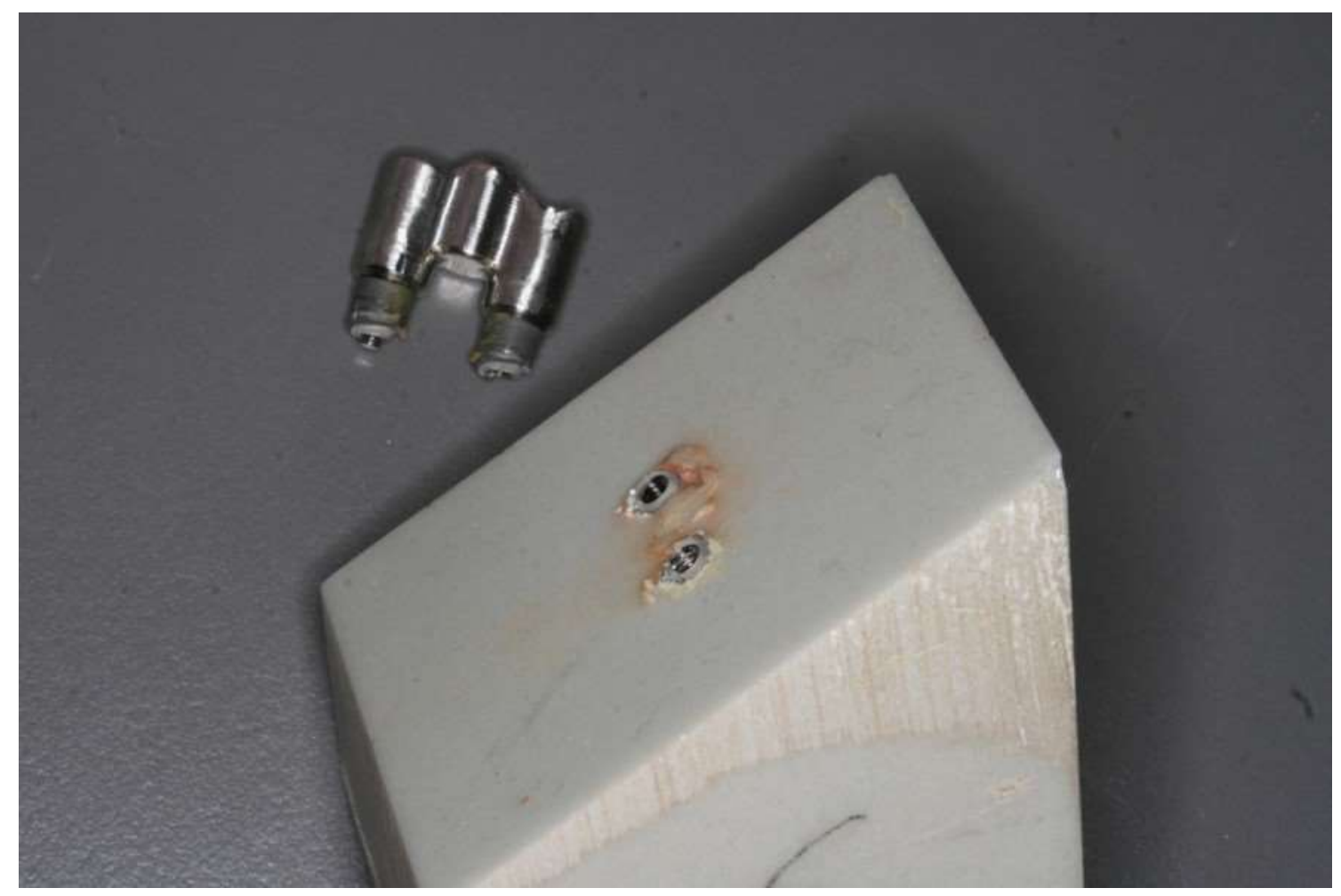


Figure 11

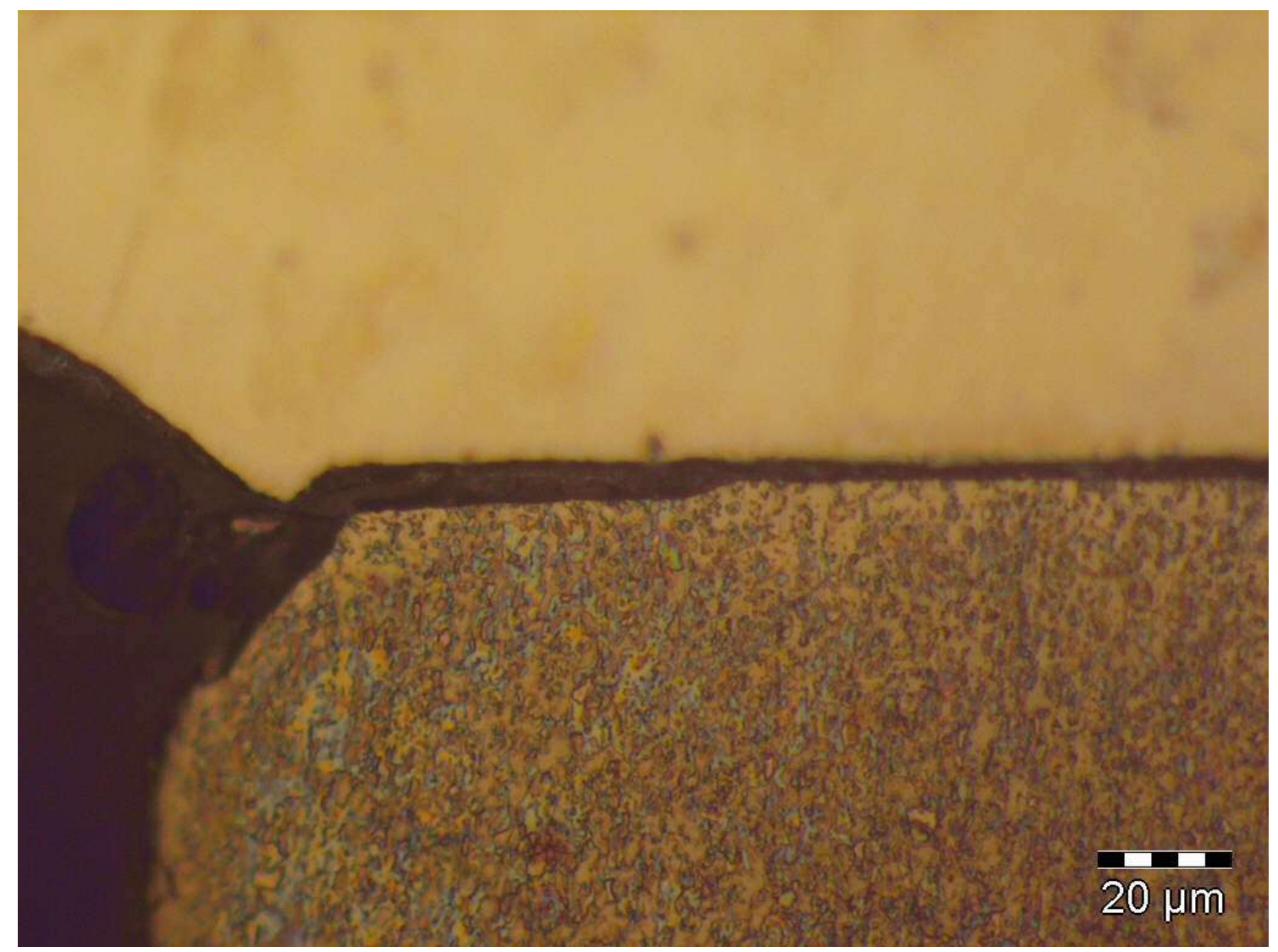


Figure 12

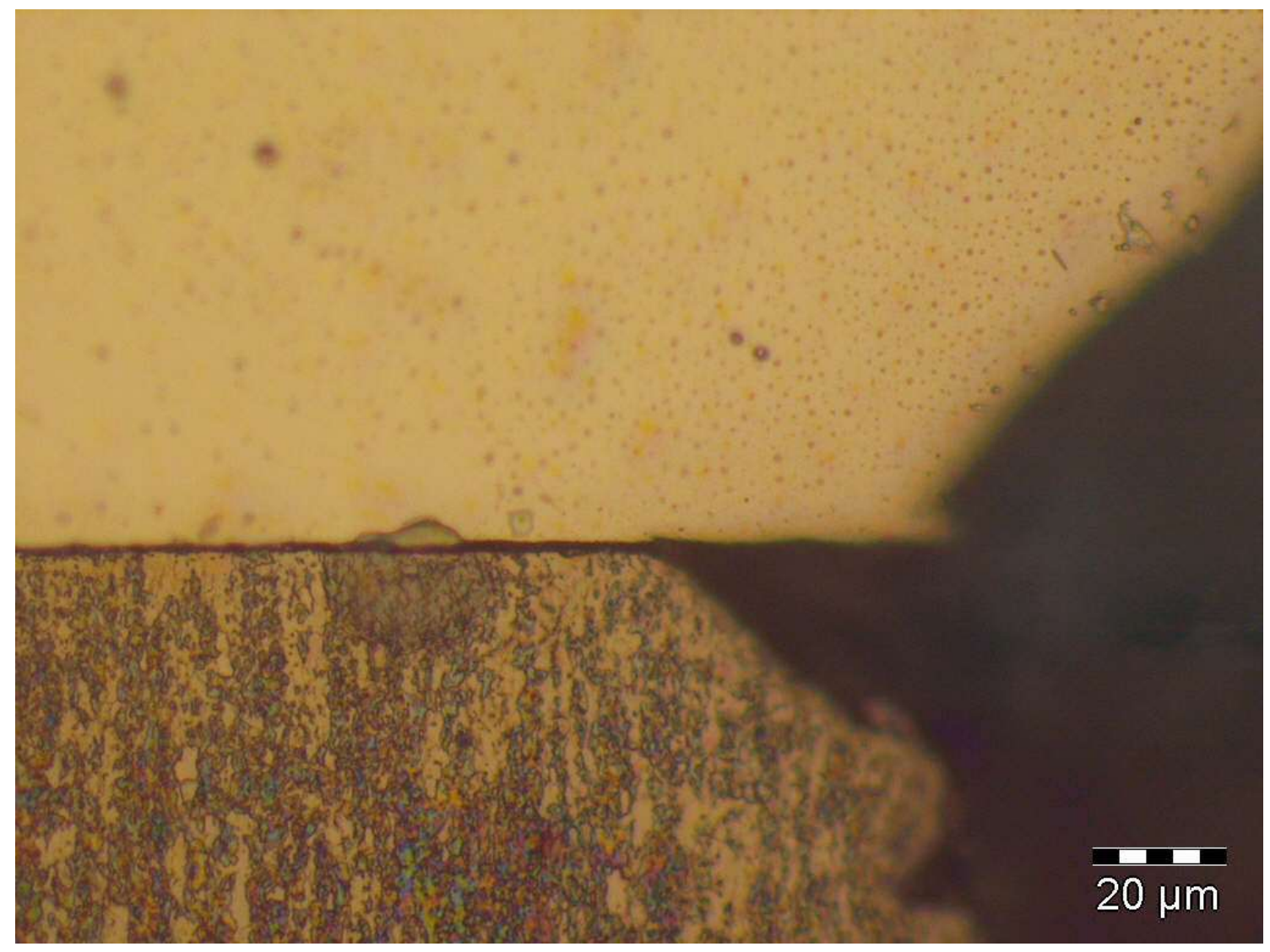


Figure 13

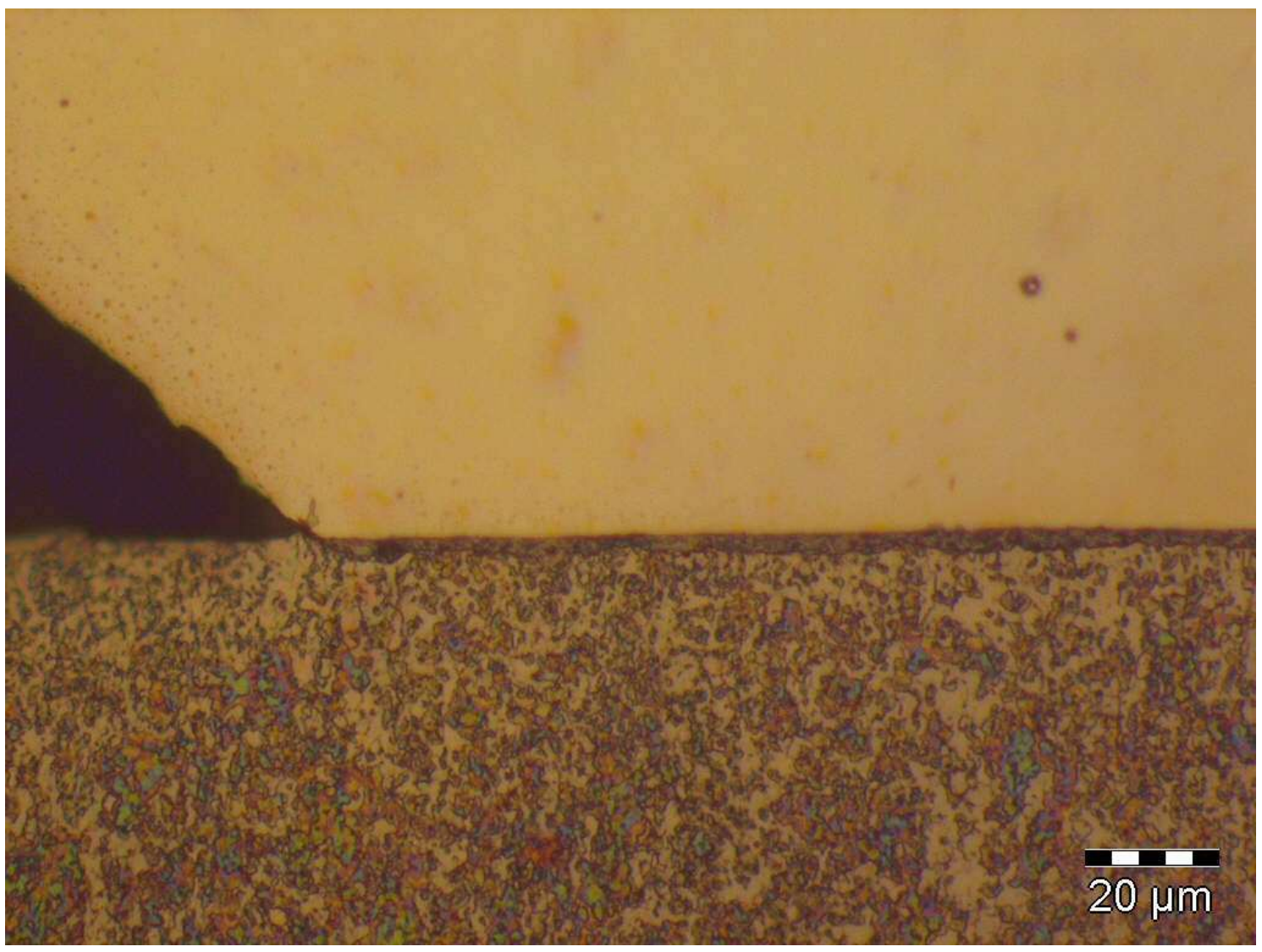


Figure 14

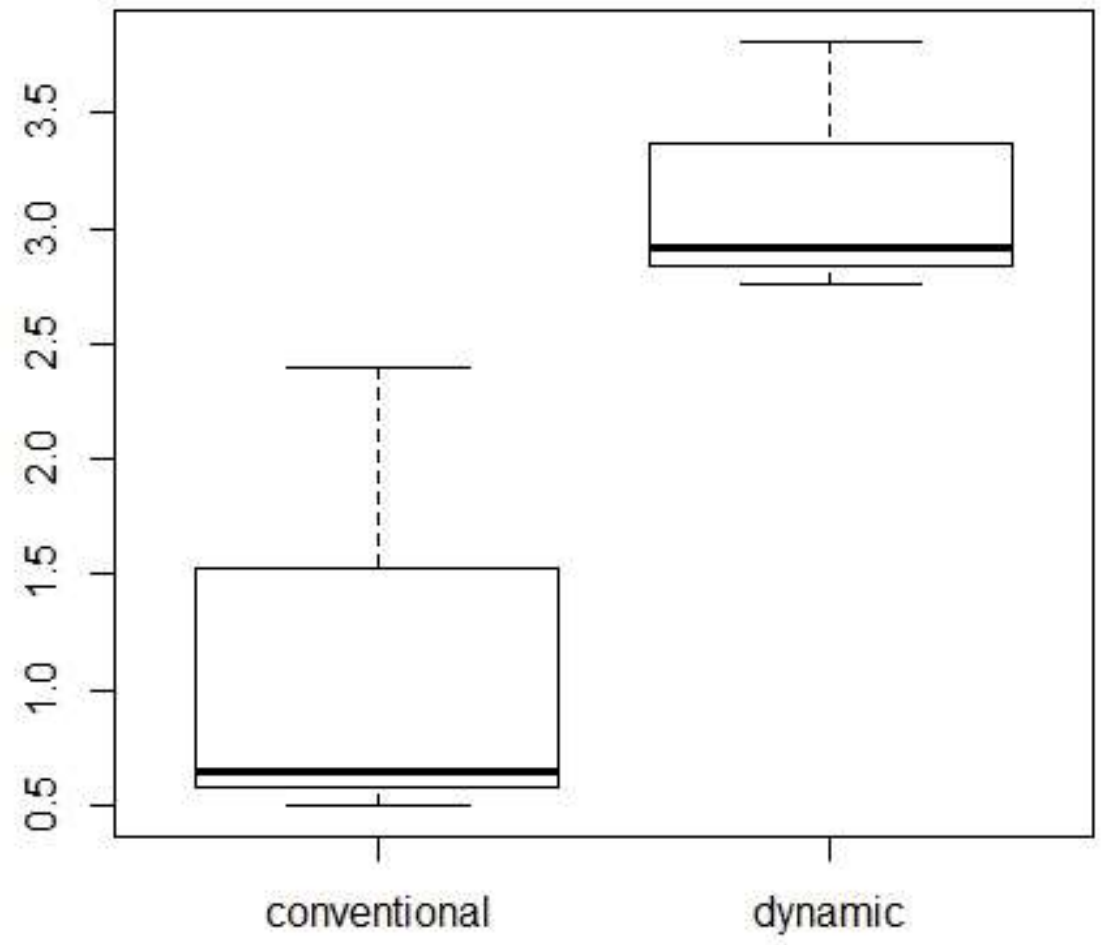


Figure 15

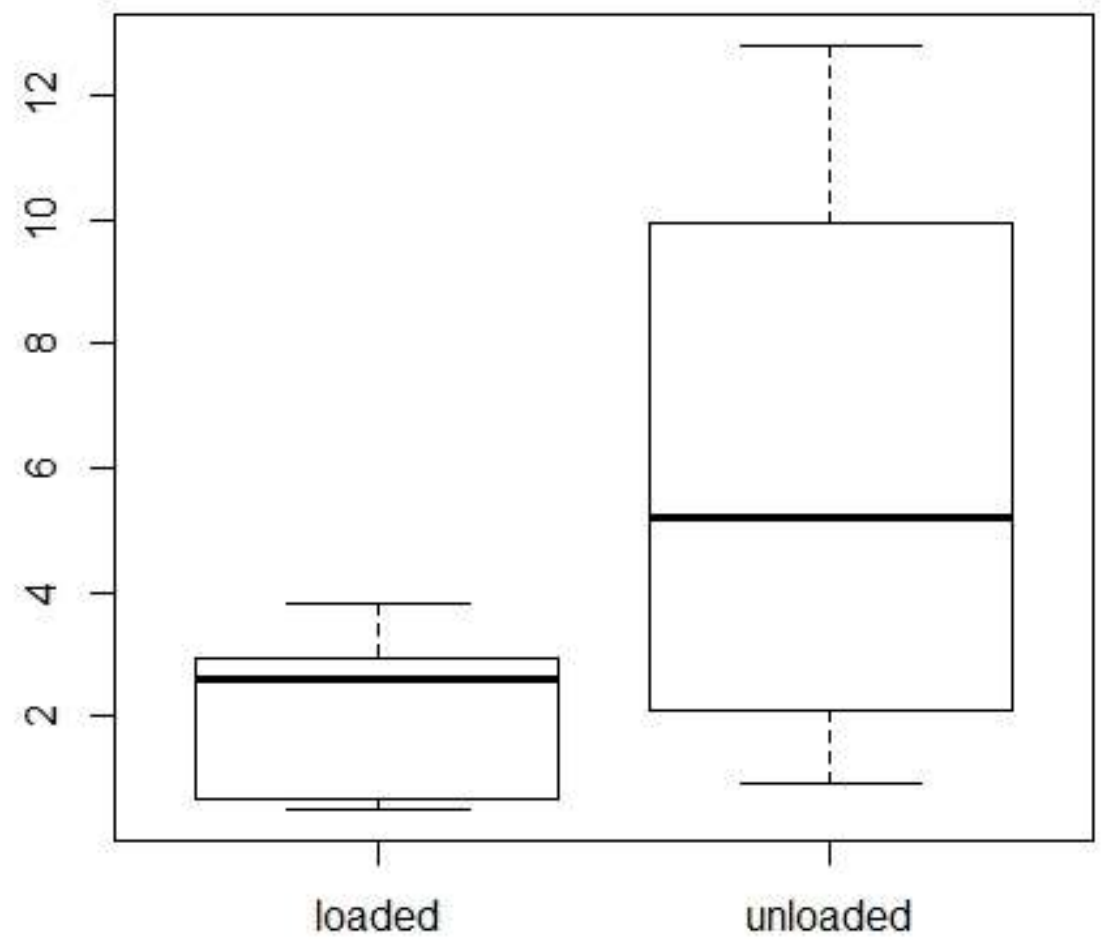

FIGURE CAPTIONS 
Figure 1 - Dynamic abutment screw channel geometry. Sagittal cut of the assembly implant-screw-framework, showing the screw channel following a direction with an angulation of $20^{\circ}$ with the implant major axis.

Figure 2 - Screw differences. Comparison between conventional (left) and dynamic screw (right) geometries.

Figure 3 - Screw differences. Comparison between conventional $1.2 \mathrm{~mm}$ hexagonal screw head (left) and dynamic screw head (right) geometry.

Figure 4 - Screwdriver for dynamic screws.

Figure 5 - Samples preparation and positioning. Silicone mold, acrylic resin prototype obtained by stereolithography and embedding material.

Figure 6 - Samples preparation and positioning. Specimens on testing machine and supporting tools according to ISO 14801.

Figure 7 - Samples preparation and positioning. Specimen magnification showing both different abutments (On the left the CA and on the right the DA) and the semi-sphere for the load appliance. 
Figure 8 - Samples for optical microscopy. A conventional screw channel abutmentscrew-implant complex is shown embedded in transparent epoxy resin for the microscopy analysis of the IAM.

Figure $9-\mathrm{S}-\mathrm{N}$ curve. Chart showing the applied load as a function of the number of cycles. When the samples reached 5 million cycles the test was interrupted.

Figure 10 - Example of a fractured sample where it can be seen the epoxy resin base and the fractured implants still connected to the prosthetic framework. The implants fracture occurred at the embedment level, reason why it is possible to observe the fractured part of the implant body still embedded in the resin.

Figure 11- Optical microscopy images. Optical microscope image showing the IAM on specimen L-8, conventional abutment, with a 1,000x magnification and a calculated dimension of $2.44 \mu \mathrm{m}$.

Figure 12 - Optical microscopy images. Optical microscope image showing the IAM on specimen L-8, dynamic abutment, with a 1,000x magnification and a calculated dimension of $2.76 \mu \mathrm{m}$. 
Figure 13 - Cold welding. Optical microscopic image of specimen L-9 for conventional abutments. A cold welding is suggested. However, SEM images could clarify IAM dimensions.

Figure 14 - Boxplot of the obtained measurements for the conventional loaded and dynamic loaded subgroups.

Figure 15 - Boxplots of the obtained measurements under unloaded and loaded conditions. 